\title{
List of Examples
}

Example 1 Transcription of shogg from the ji of the

[Chū no Mai], as sung by Issō Yukihiro

Example 2 Transcription from the ji of the [Chū no Mai], as performed by Issō Yukihiro

Example 3 Transcription of the ryo-chü-kan structure of the [Banshiki Haya-mai]

Example 4 Transcriptions of theoretical and actual performances of the [Michiyuki]

Example 5 Transcriptions of theoretical and actual performances of the [Sageuta]

Example 6 Transcriptions of theoretical and actual performances of the [Ageuta]

Example 7 Transcriptions of theoretical and actual performances of the ryo-chī-kan structure of the [Chū no Mai] 
